\title{
NOTAS MARGINAIS SOBRE SUBJETIVIDADE E EDUCAÇÃO EM TEMPOS MODERNOS LÍQUIDOS
}

\section{MARGINAL NOTES ON SUBJECTIVITY AND EDUCATION IN NET MODERN TIMES}

\author{
Alex Sander da Silva ${ }^{1}$ \\ Lucas Santiago Costa ${ }^{2}$
}

\begin{abstract}
Resumo: Este texto é um ensaio que busca abordar o conceito educacional a partir do enfrentamento da subjetividade e da alteridade. A proposta refere-se a um pensamento crítico que orienta uma possível reflexão sobre a questão das fundações educacionais nos tempos líquidos modernos, na perspectiva de Zygmunt Bauman. Nesse sentido, cabe-nos fazer uma pergunta: como pensar a Educação neste momento em que aspectos de uma crise de fundamentos nas diretrizes pedagógicas da Educação contemporânea florescem cada vez mais? Pensar em subjetividade e alteridade à luz do pensamento de Bauman é uma tarefa que não pode ser evitada por algumas categorias potencialmente formativas de subjetividade no pensamento contemporâneo, na perspectiva da modernidade líquida.
\end{abstract}

Palavras-chave: Subjetividade, Alteridade, Modernidade Líquida, Educação

\begin{abstract}
This text is an essay that seeks to approach the educational concept from the confrontation of subjectivity and otherness. The proposal refers to a critical thinking that guides a possible reflection on the issue of educational foundations in modern liquid times, from the perspective of Zygmunt Bauman. In this sense, it is up to us to ask a question: how to think about Education in this time in which aspects of a crisis of fundamentals in the pedagogical guidelines of contemporary Education flourish more and more? Thinking about subjectivity and otherness in the light of Bauman's thought is a task that cannot be avoided by some potentially formative categories of subjectivity in contemporary thought, in the perspective of liquid modernity.
\end{abstract}

Keyword: Subjectivity, Alterity, Liquid Modernity, Education

\section{Notas introdutórias}

\footnotetext{
${ }^{1}$ Doutor em Educação pela Pontifícia Universidade Católica do Rio do Sul (PUC-RS). Professor na Universidade do Extremo Sul Catarinense, UNESC, SC-Brasil. E-mail: alexsanders@unesc.net

2 Mestrando em Educação do PPGE da Universidade do Extremo Sul Catarinense, UNESC, SC-Brasil. E-mail: lucassantiagocosta21@gmail.com
}

Revista Devir Educação, Lavras, vol.4, n.1, p.250-262 jan./jun., 2020. 


\section{OO DEVIR EDUCAÇÃO}

ISSN: 2526-849X

A dispersão da atividade educacional tem demonstrado sua fragilidade no que tange o próprio conceito educativo; tanto a reformulação dos sistemas de ensino quanto os fundamentos epistêmicos sugerem "novos" rumos nas orientações pedagógicas. Porém a relação de saberes e interesses que vêm se constituindo nas relações pedagógicas, que se configuram, atualmente, num verdadeiro mudancismo ${ }^{3}$ acadêmico e em inúmeros mecanismos de autopreservação de si.

Face à multiplicidade das orientações pedagógicas, não se pode tratar o conceito educativo como um corpo de saberes já à disposição para serem transmitidos. É preciso um momento de reflexão crítica sobre certos "devaneios pedagógicos", na forma de compreender a própria Educação. Nesse sentido, cabe-nos colocar uma questão: Como pensar uma educação neste tempo em que florescem cada vez mais aspectos de uma crise de fundamentos nas orientações pedagógicas da formação contemporânea?

Nesses termos, o objetivo aqui é repensar o conceito educacional a partir do enfrentamento da modernidade líquida pensada por Bauman, e refletir sobre as temáticas da subjetividade e da alteridade, que orientem uma possível reflexão sobre esses mudancismos existentes nas elaborações pedagógicas atuais. O intuito é pensar, sobretudo, no que tange como a subjetividade e a alteridade se constituem numa tarefa educativa, que não pode se furtar de algumas categorias potencialmente pedagógicas, em tempos a que podemos chamar, como Bauman definiu: líquidos.

\section{Notas sobre a modernidade líquida em Bauman}

Vivemos tempos de transformações constantes. Transformações essas que ocorrem nos âmbitos políticos, econômicos e sociais. As mudanças na mentalidade das gerações já não são tão distantes como eram outrora. Aliás, o período que caracteriza e distingue uma geração de outra é extremamente curto. Estudiosos como Jürgen Habermas (2000); François Lyotard (1998); David Harvey (2006), Zygmunt Bauman (2001), se dedicaram, além de compreender a modernidade como fenômeno histórico, a poder decodificar de forma teórica o mundo contemporâneo, confuso e confusamente percebido, por assim dizer.

\footnotetext{
${ }^{3}$ Moraes e Duayer (1997) levantam a dúvida sobre esse mudancismo que perpassa as elaborações teóricas e se interrogam se isso não seria uma expressão do misto de futuro e ausência de futuro, manifesto no uso indiscriminado dos prefixos que viraram "moda", tais como: "pós", "neo" e "anti".
}

Revista Devir Educação, Lavras, vol.4, n.1, p.250-262 jan./jun., 2020. 


\section{OO DEVIR EDUCAÇÃO}

ISSN: 2526-849X

Referimo-nos à experiência da Modernidade Ocidental que se configura a partir do Renascimento (século XVII), caracterizando-se por alguns elementos, tais como: racionalidade secularizada; distanciamento da visão religiosa do mundo; atividade intensa do saber que se manifesta no desenvolvimento técnico fecundado pela ciência, entre outros fatos importantes que atingem, de modo particular, a economia, a política e a cultura. Os ideais da modernidade se expressam de forma significativa no Iluminismo, que se situa a partir do século XVIII e busca na razão a possibilidade da autonomia humana (CASSIRER, 1997; CHÂTELET, 1994).

A intensificação da crítica à modernidade é colocada, sobretudo, como uma espécie de atmosfera cultural, resultante das elaborações, das transformações científicas, tecnológicas e culturais, da globalização dos mercados, desenhando-se em configurações complexas dessas mudanças. Nessa concepção, esvazia-se o papel da razão e das pretensões teóricas que se direcionam pelos grandes sistemas de pensamento e orientam-se pelos ditames da fragmentação epistemológica.

Esse contexto é objeto de estudo do teórico Zygmunt Bauman, que busca compreender as mudanças substanciais entre o que, até então, consideramos modernidade e o que pode ser entendido como elementos da pós-modernidade. Ao ocuparmos um período cronológico definido de forma distinta por autores distintos, a modernidade foi definida e pensada de formas distintas. Estamos na modernidade, no entanto, em qual modernidade? A pós-moderna? A modernidade tardia? A modernidade líquida? O termo e as concepções a serem utilizadas variam muito. Contudo a essência da mutabilidade constante está presente em qualquer categoria apresentada ou defendida por inúmeros autores. Seja em livros de autores consagrados (Jürgen Habermas; François Lyotard; David Harvey, Zygmunt Bauman), ou em outras produções acadêmicas.

Bauman dedicou parte da sua carreira intelectual tentando decifrar as lógicas contemporâneas, na cultura, no modo de vida e, particularmente, nos desafios desse nosso tempo, envolvido pela lógica da produção material da vida no capitalismo. Essas lógicas definem, de forma apropriada ou não, tanto os fatos quanto as motivações das ações que nos cercam, bem como as exigências no caráter formativo educacional. O intelectual polonês Zygmut Bauman (1925-2017) foi um grande pensador da modernidade, um analista perspicaz de temas contemporâneos, tais como: cultura, consumo, capitalismo, amor, entre tantos 


\section{OO DEVIR EDUCAÇÃO}

ISSN: 2526-849X

outros. Mas sua dedicação se destaca em pensar a temática da modernidade, sobretudo no seu desenrolar na contemporaneidade.

Onde nos enquadramos? Podemos ser enquadrados? Que período é esse em que vivemos? Podemos defini-lo? Esses são exemplos de questionamentos interessantes para a análise do cenário do qual Bauman se valeu. Afinal, para se discursar sobre um lugar ou um tempo, é importante tornar claro de que lugar e de qual período estamos falando. A localização temporal para a compreensão de uma concepção é de um tema. E não é diferente com a fase atual da modernidade.

Mas o que é a modernidade? A modernidade começa a ser percebida a partir das transformações do mundo ocidental, com o advento do Renascimento e do desenvolvimento da burguesia. São fenômenos que contribuíram com o seu desenvolvimento a Revolução Francesa e a Industrial. Essa modernidade possui um caráter que implica em um modo de ser. Segundo Berman (2000, p. 15):

Ser moderno é encontrar-se em um ambiente que promete aventura, poder, alegria, crescimento, autotransformação e transformação das coisas em redor - mas ao mesmo tempo, ameaça destruir, tudo o que temos, tudo o que sabemos, tudo o que somos.

Justamente pelo seu caráter "inovador", a Modernidade pode ser percebida como "autodestrutiva", para o mantimento do seu mecanismo de funcionamento. Ou seja, fazendo com que os paradigmas, até certo ponto sólidos, que ela constrói, venham a ser desconstruídos por novos paradigmas, para que ela se perpetue, principalmente, do ponto de vista econômico.

Nos últimos anos, a modernidade passou a um estágio em que a sua essência de mutabilidade constante se intensificou de maneira incontestável, gerando, assim, um estado de incertezas muito claro nas instâncias da existência. Este estágio em que estamos inseridos é denominado de maneiras distintas. Alguns chamam esse período de Pós-Modernidade. Mas o que isso significa? Para Eagleton (1996, p. 7):

Pós-Modernidade é uma linha de pensamento que questiona as noções clássicas de verdade, razão, identidade e objetividade, a ideia de progresso ou emancipação universal, os sistemas únicos, as grandes narrativas, ou os sistemas definitivos de explicação. [...] vê o mundo como contingente, gratuito, diverso, instável, imprevisível, um conjunto de culturas ou interpretações desunificadas gerando certo grau de ceticismo em relação à

Revista Devir Educação, Lavras, vol.4, n.1, p.250-262 jan./jun., 2020. 


\section{OO DEVIR EDUCAÇÃO}

ISSN: 2526-849X

objetividade da verdade, da história e das normas em relação às idiossincrasias e a coerência de identidades.

Posto isso, podemos perceber que o caráter desta fase da modernidade é frágil sob vários aspectos, possibilitando a geração de insegurança diante das contingências postas claramente neste cenário dotado de rupturas irrefreadas. No contexto da discussão teórica sobre essa fase da Modernidade é que o sociólogo Zygmunt Bauman aparece.

Escritor profícuo, Bauman colocou o seu nome dentre os principais autores da modernidade contemporânea. Na década de 1990, Bauman trabalhou com o conceito categórico de "Pós-Modernidade", escrevendo inclusive, duas obras com esses termos: "Ética Pós-Moderna" e o "Mal-Estar da Pós-Modernidade". No entanto mudou a categoria de análise para a metáfora "Modernidade Líquida". Bauman entendeu que o termo anterior não definiria de forma cabível o conceito referente ao período vigente. Para ele, a "PósModernidade" apontaria para uma superação da modernidade, sem, contudo, deixar preciso em qual período nos encontramos.

A passagem da fase "sólida" da modernidade para a "líquida" - ou seja, para uma condição em que as organizações sociais (estruturas que limitam as escolhas individuais, instituições que asseguram a repetição de rotinas, padrões de comportamento aceitável) não podem mais manter sua forma por muito tempo (nem se espera que o façam), pois se decompõem e se dissolvem mais rápido que o tempo que leva para moldá-las (BAUMAN, 2007, p. 7).

Bauman (2001) tematiza suas reflexões em torno do tema da modernidade, como sendo uma leitura da contemporaneidade com a metáfora dos fluídos, em contraste com os sólidos. Ou seja, a modernidade teria construído alguns sólidos, que estão passando por um processo de liquefação, de desconstrução contínua, gerando uma instabilidade nunca vista antes na história da sociedade ocidental. Com isso, Bauman procura indicar que, na modernidade líquida, não há lugar para solidez eterna, o sujeito moderno, na busca de si, sem a segurança de categorias superficiais, implica.

Conforme Bauman (2001, p. 12):

O "derretimento dos sólidos", traço permanente da modernidade, adquiriu, portanto, um novo sentido, e, mais que tudo, foi redirecionado a um novo alvo, e um dos principais efeitos desse redirecionamento foi a dissolução das forças que poderiam ter mantido a questão da ordem e do sistema na agenda política. Os sólidos que estão para ser lançados no cadinho e os que estão

Revista Devir Educação, Lavras, vol.4, n.1, p.250-262 jan./jun., 2020. 


\section{OO DEVIR EDUCAÇÃO}

ISSN: 2526-849X

derretendo neste momento, o momento da modernidade fluida, são os elos que entrelaçam as escolhas individuais em projetos e ações coletivas - os padrões de comunicação e coordenação entre as políticas de vida conduzidas individualmente, de um lado, e as ações políticas de coletividades humanas, de outro.

Em Bauman (2001), a modernidade não foi superada, e sim vive um estágio diferente, o de liquidez. Ele apresenta uma leitura da contemporaneidade com a metáfora dos fluídos em contraste com os sólidos. Ou seja, a modernidade teria construído alguns sólidos, que estão passando por um processo de liquefação, de desconstrução contínua, gerando uma instabilidade nunca vista antes na história da sociedade ocidental.

Com isso podemos intuir, com o autor, que, no mundo líquido, tudo é mutável, em termos coloquiais, nada veio para ficar. Como Bauman disse em outro momento "um ambiente líquido é inóspito ao planejamento, investimento e armazenamento de longo prazo" (BAUMAN, 2008, p. 45). Em seu texto Modernidade líquida e liberdade consumidora: o pensamento crítico de Zygmunt Bauman Tiago de Oliveira Fragoso (2011) trata sobre relações políticas nestes tempos líquidos. No seu dizer:

O poder na era da liquidez não é mais aquele que se materializava na disciplina da fábrica fordista, na torre de controle panóptica, na administração pública. O poder agora é extraterritorial, o seu objetivo não é mais impor à sociedade um ordenamento rígido, mas simplesmente, através de uma aceleração compulsiva do tempo e do domínio total do espaço, expor todos os lugares do planeta à livre ação da globalização econômica do mercado capitalista. A elite global não tem mais o interesse de governar a partir de um território, pois ela é cada vez mais desterritorializada e inacessível, vivendo em fortalezas fortificadas por sistemas de segurança high-tech, as quais são meras paragens de sua contínua mobilidade espacial (FRAGOSO, 2011, p. 111).

E é justamente nesse viés, ou seja, nesse contexto de efemeridade, dúvidas, inconstâncias e oscilações políticas, cada vez mais "desterritorializado", em que estamos vivendo. Cada vez mais, as relações políticas se demonstram fluidas, líquidas, de modo que Bauman é certeiro em sua análise. A modernidade é um fenômeno novo, do ponto de vista da história, bem como a modernidade líquida o é. A apreensão desses conceitos, vinculada à percepção de questões ligadas ao contexto educacional são de um valor irreparável.

\section{Notas sobre subjetividades e alteridade na educação em tempos líquidos}

O desenvolvimento do conceito de sujeito significou, na modernidade, a partir do século XVII, mudanças nos termos da filosofia, o que engendrou a consciência de si, de 


\section{OO DEVIR EDUCAÇÃO}

ISSN: 2526-849X

forma reflexiva. Na ciência, o sujeito epistemológico com controle da natureza pelo conhecimento das leis que a regem. O reconhecimento do outro implicou uma necessidade do reconhecimento de si mesmo nesse período. Porém, na contemporaneidade, o sujeito inscreve-se na ideologia de uma ciência econômica regida por um circuito fechado de "fenômenos objetivos", os do mercado mundial, forma moderna do destino ao que se submetem.

Essa aferição é a da heteronomia produzida pelo pensamento único, pelo reino da uniformidade e da unanimidade que sacrifica a alteridade. No caminho de Nietzsche, a massa constitui-se segundo um espírito gregário acrescido, agora, de um traço especial: trata-se de indivíduos "atomizados", encapsulados em seu próprio isolamento. Isolados, também, no sentido de seu desenraizamento - não de uma tradição, mas de qualquer tradição, seres gregários e atomizados, posto que destituídos de referências comuns.

Desse modo, também a individualidade, cuja defesa como o pólo do nãoidêntico torna-se necessário empreender contra sua completa absorção na impessoalidade da integração identitária, é apenas mais um dos cacos, uma das ruínas e um dos escombros desse real evanescente, cujo mosaico a dialética negativa se esforça por recompor em sua fugacidade [...] É preciso não esquecer, portanto, que dialética negativa, tal como a realiza Adorno, apreende o conceito de indivíduo como formação histórica da subjetividade burguesa (GIACÓIA JR., 2001, p. 75).

$\mathrm{Na}$ sociedade de massa, tudo passa a ser tomado segundo o valor de troca. Todo indivíduo é intercambiável, dispensável. Massa e classes sociais dissociam-se, pois é característica da primeira não somente a ausência de pensamento autônomo, ou de pensamento propriamente dito, mas, de maneira mais essencial, ausência de interesse comum. Nesse sentido, Nietzsche (2003, p. 103) afirmava: "é preciso libertar o homem moderno da maldição do moderno".

Essa perspectiva constitui-se na possibilidade de atualizar a análise de Bauman em suas categorias potencialmente vinculadas às análises educacionais contemporâneas. A metáfora da liquidez nos remete ao entendimento de que uma das grandes características (e talvez a maior) dessa fase da modernidade contemporânea é a fragilidade e a velocidade de dissolução dos sólidos, ou seja, as estruturas postas ao longo do tempo. O que temos é uma formalização racional reduzida e vinculada ao poder, a dominação e a exploração, conhecida pela sociedade moderna no aspecto da criação/produção/representação de uma vida líquida.

Revista Devir Educação, Lavras, vol.4, n.1, p.250-262 jan./jun., 2020. 


\section{OO DEVIR EDUCAÇÃO}

ISSN: 2526-849X

Vivemos em uma sociedade cada vez mais exigente com os construtos de relações líquidas que convocam seus membros a buscarem novas maneiras de atuar nas relações de sobrevivência. Se pensarmos na aceleração técnico-científica, contraditoriamente, podemos nos orgulhar da capacidade criadora e reprodutora do ser humano, contudo, isso está levando a uma instrumentalização do próprio sujeito, configurado por meio de uma razão instrumental de que falam Adorno e Horkheimer na Dialética do Esclarecimento (1985).

Parece estar em evidência, hoje, a ideia de um outro negado, ou seja, um outro destituído de uma realização efetiva de alteridade. Notamos muito mais, em nosso cotidiano, manifestações de eliminação desse outro, sobretudo, por meio das discriminações racial, social e da exclusão. Dessa forma, a alteridade deveria estar, potencialmente, nos planos de uma educação emancipadora e de resistência à eliminação do outro enquanto outro. $\mathrm{O}$ inteiramente outro do mundo administrado, com suas massas de homens e mulheres isolados e supérfluos, vive sem reciprocidade: nele e para ele os seres humanos não são substituíveis, tampouco intercambiáveis. Essa "reciprocidade entre insubstituíveis" é tarefa da educação.

Desse modo, tendo por base algumas premissas de Bauman, podemos considerar que os processos educativos não se restringem apenas ao momento da instrução, vão mais além. Se não estamos atentos a essas configurações sociais, elas passam despercebidas às relações alienantes e ideológicas que, mecanicamente, automatizam o sujeito como peça de uma engrenagem social, fechada em si mesma e como consumidora dos espetáculos padronizados pelo consumo. Estamos condenados a essa padronização já no constituir da individualização em que nos coloca Bauman. Ou seja,

Não se engane: agora, como antes - tanto no estágio leve e fluido da modernidade, quanto no sólido e pesado - a individualização é uma fatalidade, não uma escolha. Na terra da liberdade individual de escolher, a opção de escapar a individualização e de se recuperar a participar do jogo da individualização está decididamente fora da jogada. A autocontenção e autossuficiência do indivíduo pode ser outra ilusão (BAUMAN, 2001, p. 48).

Bauman (2001) desenvolve uma crítica dissolvente da totalidade sistêmica do pensamento moderno. Para ele, o princípio de totalidade impede o reducionismo objetivista $e$ subjetivista e veda a dissolução do particular no universal. O momento atual da modernidade, a modernidade líquida, é caracterizado justamente pela dissolução das forças ordenadoras que permitiam ativamente reenraizar e reencaixar os antigos sólidos em novas formas sociais 


\section{OO DEVIR EDUCAÇÃO}

ISSN: 2526-849X

modernas (FRAGOSO, 2011). A metáfora da liquidez impede a reconciliação do sujeito a uma ordem social obcecada pela produção dele, do equivalente universal no valor de troca.

Nas premissas de Bauman (2001), podemos considerar que os processos educativos não se restringem apenas ao momento de instrumentalização da subjetividade e da alteridade. Com isso, procura-se indicar que a educação deve mergulhar na mais profunda busca de si, sem a segurança de categorias superficiais. Para ele, a educação não pode ficar presa a modelos ideais de racionalidade.

A crença do ingresso da humanidade num tipo de cultura que levaria ao progresso e libertação dos sujeitos por meio do conhecimento científico tem demonstrado seu lado implacável de dominação das subjetividades. Mesmo com a crescente automação dos processos tecnológicos, com a informatização, com a alta velocidade de circulação das informações, com a ampliação democrática da cultura e do conhecimento, tem-se levado a humanidade a profundos processos de crises estruturais de organização social.

Essa questão está colocada nos termos se analisarmos a produção material e histórica da "subjetividade", ou, como Bauman (2009) sugere, de individualização como uma categoria dinâmica. De acordo com Almeida, Gomes e Bracht (2009), a crítica de Bauman evidencia que, enquanto não se modificarem as condições objetivas, haverá sempre uma lacuna entre as pretensões educacionais formativas e as realizações propriamente objetivas.

Nesse sentido, o problema educacional pode ser pensado na íntima ligação ao problema da formação do sujeito, da sua subjetividade em tempos denominados líquidos. Por isso, pautar uma reflexão apoiada nas elaborações de Bauman (2001) nos remete à necessidade, apontada por ele, de um diagnóstico crítico da sociedade contemporânea e da educação. Em Bauman (2001), podemos pensar que a educação implica emancipação, que não se reduz ao mero ajuste ao domínio da subjetividade presa aos ditames sólidos da sociedade industrializada.

Nesse sentido, com Bauman (2001), a emancipação - promovida pela instituição escolar - não deve conduzir à perda da individualidade de um conformismo uniformizador, ou seja, perder-se do seu objetivo de emancipação, mas, sim, estar atento à educação escolar como um processo educativo que reproduza essa uniformização da formação cultural exclusivamente idealista e reificada. Conforme explicam Almeida, Gomes e Bracht (2009, p. $48)$,

Revista Devir Educação, Lavras, vol.4, n.1, p.250-262 jan./jun., 2020. 


\section{OO DEVIR EDUCAÇÃO}

ISSN: 2526-849X

[...] a educação por sua vez, uma declaração da incompetência social das massas e na aposta na ditatura do "professorado" (déspotas ilustrados), guardiões da razão, das maneiras e do bom gosto. Não é de estranhar, portanto, que Bauman, nesse livro, tenha concebido a educação escolarizada como o conceito e a prática de uma sociedade amplamente administrada.

A apreensão desses conceitos, vinculada à percepção de questões ligadas ao contexto educacional são de um valor irreparável. Entender a condição do professor, de certa forma é assimilar, também, a condição da educação. Nesses termos, colocamos, aqui, uma reflexão que desvele os termos das determinações sociais objetivas e subjetivas à qual os sujeitos sociais estão submetidos, inclusive no âmbito escolar.

A função social da educação (de modo particular, da escola), somente se explicita à medida que se desenvolve a perspectiva de sua apreensão em seu duplo caráter material. Nesse sentido, o que se observa, de um lado, atualmente, no Brasil, é a progressiva redução dos investimentos e dos impasses das políticas educacionais. Por outro lado, as pseudosoluções, aparentemente desconexas, que estão organicamente articuladas como peças de uma engrenagem social contaminada pelas relações de mercados educacionais capitalistas.

O pensamento crítico de Bauman $(2001 ; 2003)$ parte de uma brecha entre a imposição objetiva e as determinações subjetivas para legitimar a possibilidade educativa. Esse prisma proposto é mister e atual na defesa de uma educação contra a dominação e essa premissa está cada vez mais urgente. A metáfora da liquidez se vinculou aos ditames das políticas de desmonte da educação pública, apregoada pelos ditames do capital econômico. É urgente, também, enfrentar e buscar superar os problemas que estão na origem dos crimes acometidos contra a vida.

Enfim, a escola, o professor e a professora, que buscam considerar a constituição de sujeitos emancipados, podem quebrar os esquemas autoritários e centralizadores da educação, de ensino e de formação, sob forma de repasse das "verdades imutáveis", para abrir espaços constitutivos da reflexão crítica. O que se quer realçar do exposto é que a luta pela defesa da educação, contra seu caráter mercadológico, é uma necessidade efetiva para uma nova estratégia social. 


\section{OO DEVIR EDUCAÇÃO}

ISSN: 2526-849X

Essa perspectiva sinaliza os dilemas e conflitos face ao substancial da educação da classe trabalhadora. A via de acesso a esse substancial é o reconhecimento do processo de reprodução das relações materiais vigentes e de resistência a ele.

\section{Notas finais}

$\mathrm{Na}$ contemporaneidade, a forma de percepção das coletividades e o desenvolvimento das diferentes formas de cultura são profundamente marcados pela presença da diversidade cultural. No entanto, é necessário reconhecer, além do aparente acesso democrático às produções culturais, a condição de "marginalização" imposta à grande parcela das pessoas, das crianças e dos jovens. Em outras palavras, é preciso estar atento à condição deliberada da exploração camuflada pela ideologia e do seu predomínio na produção de consciências alienadas, voltadas apenas para o consumo.

No pensamento crítico e criativo de Bauman, vimos resplandecer o diagnóstico desastroso desse tempo em que ele denominou de líquido. A difusão da lógica do consumo dos bens simbólicos acionados pela "vida para o consumo" não deixa de ser irônica e, por isso, Bauman (2008) asseverou que a liberação prometida pelo entretenimento decreta apenas a falência da integração irracional da coletividade. É nesse sentido que uma concepção educacional que se julga crítica precisa alertar-se sobre as discrepâncias entre os conteúdos ideológicos dessa indústria cultural do consumo e suas realizações deformativas.

O desafio é manter-se no caminho da resistência e da utopia filosófica. Essa proposta requer o caminho da contradição, que reclame elementos de uma razão crítica. Vivemos tempos, mais do que nunca, de desafios. Esperamos poder trilhar caminhos coletivos de superação da situação existente. Isso se dá pelo fortalecimento e não pelo desmonte e desvalorização das "humanidades". A defesa de uma educação emancipada passa pela valorização das ciências humanas que podem nos ajudar a nos orientar nesse mundo em tempos líquidos.

\section{Referências}

ADORNO, Theodor; HORKHEIMER, Max. Dialética do Esclarecimento: fragmentos filosóficos. Rio de Janeiro: Jorge Zahar, 1985. 


\section{OO DEVIR EDUCAÇÃO}

ISSN: 2526-849X

ALMEIDA, Felipe Quintão de. GOMES, Ivan Marcelo; BRACHT, Valter. Bauman \& a

Educação. Belo Horizonte: Autêntica, 2009. (Coleção Pensadores \& Educação).

BAUMAN, Zygmunt. Arte da vida. Rio de janeiro: Jorge Zahar, 2009.

BAUMAN, Zygmunt. Comunidade: a busca por segurança no mundo atual. Rio de Janeiro: Jorge Zahar, 2003.

BAUMAN, Zygmunt. Modernidade líquida. Rio de Janeiro: Jorge Zahar, 2001.

BAUMAN, Zygmunt. Tempos Líquidos. Rio de Janeiro: Zahar, 2007.

BAUMAN, Zygmunt. Vida para Consumo. Rio de Janeiro: Jorge Zahar, 2008.

BERMAN, Marshall. Tudo que é Sólido se Desmancha no Ar. São Paulo: Schwarcz, 2000.

CASSIRER, Ernest. A filosofia do Iluminismo. Tradução de Álvaro Cabral. 3. ed. Campinas, SP: Unicamp, 1997.

CHÂTELET, François. Uma história da razão: entrevista com Émile Nöel. Rio de Janeiro: Zahar, 1994.

EAGLETON, Terry. As ilusões do pós-modernismo. Rio de Janeiro, Zahar, 1996.

FRAGOSO, Tiago de Oliveira. Modernidade líquida e liberdade consumidora: o pensamento crítico de Zygmunt Bauman. Revista Perspectivas Sociais Pelotas, a. 1, n. 1, p. 109-124, mar. 2011.

GIACÓIA JR., Osvaldo. A ética na era da globalização à luz do pensamento de Adorno. In: LASTORIA, Luiz A. C. N.; COSTA, Berlamino C. G.; PUCCI, Bruno (orgs.). Teoria crítica, ética e educação. Piracicaba, SP; Campinas, SP: UNIMEP; Autores Associados, 2001.

HABERMAS, Jürgen. Discurso filosófico da modernidade. Lisboa: Dom Quixote, 2000.

HARVEY, David. Condição pós-moderna. Tradução de Adail Ubirajara Sobral e Maria Stela Gonçalves. 7. ed. São Paulo: Loyola, 2006.

LYOTARD, François. A condição pós-moderna. Tradução de Silviano Santiago. 5. ed. Rio de Janeiro: José Olympo, 1998. 
MORAES, Maria Celina; DUAYER, Mario. Richard Rorty: a ética pragmática do neoconservadorismo. In: HÜHNE, Leda Miranda (org.). Ética. Rio de Janeiro: SEAF, 1997.

NIETZSCHE, Friedrich Wilhelm. Escritos sobre educação. Tradução de Noéli Correia de Melo Sobrinho. Rio de Janeiro: PUC-Rio; São Paulo: Loyola, 2003. (Coleção Teologia e Ciências Humanas, Vol. 11).

Recebido em 30/04/2020

Aprovado em: 18/05/2020

Revista Devir Educação, Lavras, vol.4, n.1, p.250-262 jan.jun., 2020. 